\title{
Experimental Accuracy and Stability of Gas Outburst Experimental System
}

\author{
Yanbao Liu, ${ }^{1,2}$ Haitao Sun $\mathbb{D}^{1,2}$ Bo Wang $\mathbb{D}^{1,2,3}$ Linchao Dai $\mathbb{D}^{1,2}$ and Jie Cao ${ }^{1,2}$ \\ ${ }^{1}$ State Key Laboratory of the Gas Disaster Detecting, Preventing and Emergency Controlling, Chongqing 400037, China \\ ${ }^{2}$ China Coal Technology and Engineering Group Chongqing Research Institute, Chongqing 400037, China \\ ${ }^{3}$ School of Mechanics and Civil Engineering, China University of Mining and Technology, Xuzhou, Jiangsu 221116, China
}

Correspondence should be addressed to Haitao Sun; dreamsht@163.com and Bo Wang; 21305@163.com

Received 20 November 2020; Revised 10 January 2021; Accepted 4 February 2021; Published 25 February 2021

Academic Editor: Yi Xue

Copyright (c) 2021 Yanbao Liu et al. This is an open access article distributed under the Creative Commons Attribution License, which permits unrestricted use, distribution, and reproduction in any medium, provided the original work is properly cited.

Gas outburst is an important issue in deep coal mining. At present, the gas-rock coupling change mechanism and intensity prediction of gas outburst are not clear. The research of gas outburst simulation experiment is particularly important. The State Key Laboratory of Gas Disaster Monitoring and Emergency Technology of China independently developed a large-scale coal and gas outburst physical simulation test system. However, the influence of the design parameters of the testing machine on the stability and accuracy of the simulation experiment is unclear. The article analyzes the energy conversion in the process of gas outburst through experimental simulation phenomena and results. The experimental simulation results show that the energy released by the $\mathrm{CO}_{2}$ gas in similar materials is the most important energy source. The cracks of similar materials increase the nominal volume of similar materials, and the deformation energy stored in similar materials slightly increases. The experimental simulation results are consistent with the actual situation on site. Combined with CAE simulation analysis, the displacement and pressure of the indenter of the experimental machine remained basically unchanged during the experiment, and the system did not produce resonance. Comprehensive analysis shows that the design of the test machine meets the simulation requirements.

\section{Introduction}

China's coal production and consumption have long ranked first in the world [1]. Coal and gas outburst accidents are one of the most serious disasters that plague the safe production of underground coal mines [2,3]. Outburst accidents of large scales accounted for $32 \%$ of gas outburst accidents, and fatalities caused by such accidents accounted for $33.3 \%$ of all types of mine fatalities [4]. At the same time, China's shallow coal resources are gradually depleted, and the mining of deep coal resources is increasingly becoming a demand for the coal industry [5]. However, the coupling of coal and rock gas dynamic disasters in deep environments such as high ground stress, high gas pressure, and high ground temperature is more complicated [5-7]. Large-scale physical simulation analysis of this scientific problem is currently the most applicable research method $[1,8]$.

Coal and gas outburst is a mine dynamic disaster caused by a combination of factors such as crustal stress, gas pres- sure, and coal physical properties $[9,10]$. Once coal and gas outburst occurs, a large amount of coal is thrown into the roadway space [11]. Once a large amount of gushing gas encounters a fire source, a gas explosion will occur, which destroys the mine production system and endangers the lives of workers. The mechanism and prediction of coal and gas outburst have always been a worldwide problem that the field of coal mine safety tries to solve $[6,7]$.

The understanding of the mechanism of gas outburst is still at the stage of hypothesis and is not unified, but the research on the physical model of gas outburst is similar [12-19]. The preparation stage for gas outburst is the energy accumulation stage. The magnitude of this energy varies with the elasticity of coal [9], and the release method of elastic potential varies with the mechanical properties of coal $[2$, 12]. The occurrence and development stages of the outburst are mainly completed by the action of gas in the coal [2]. When the coal is suddenly broken, the gas quickly changes from the adsorbed state to the free $[2,12]$. At the same time, 

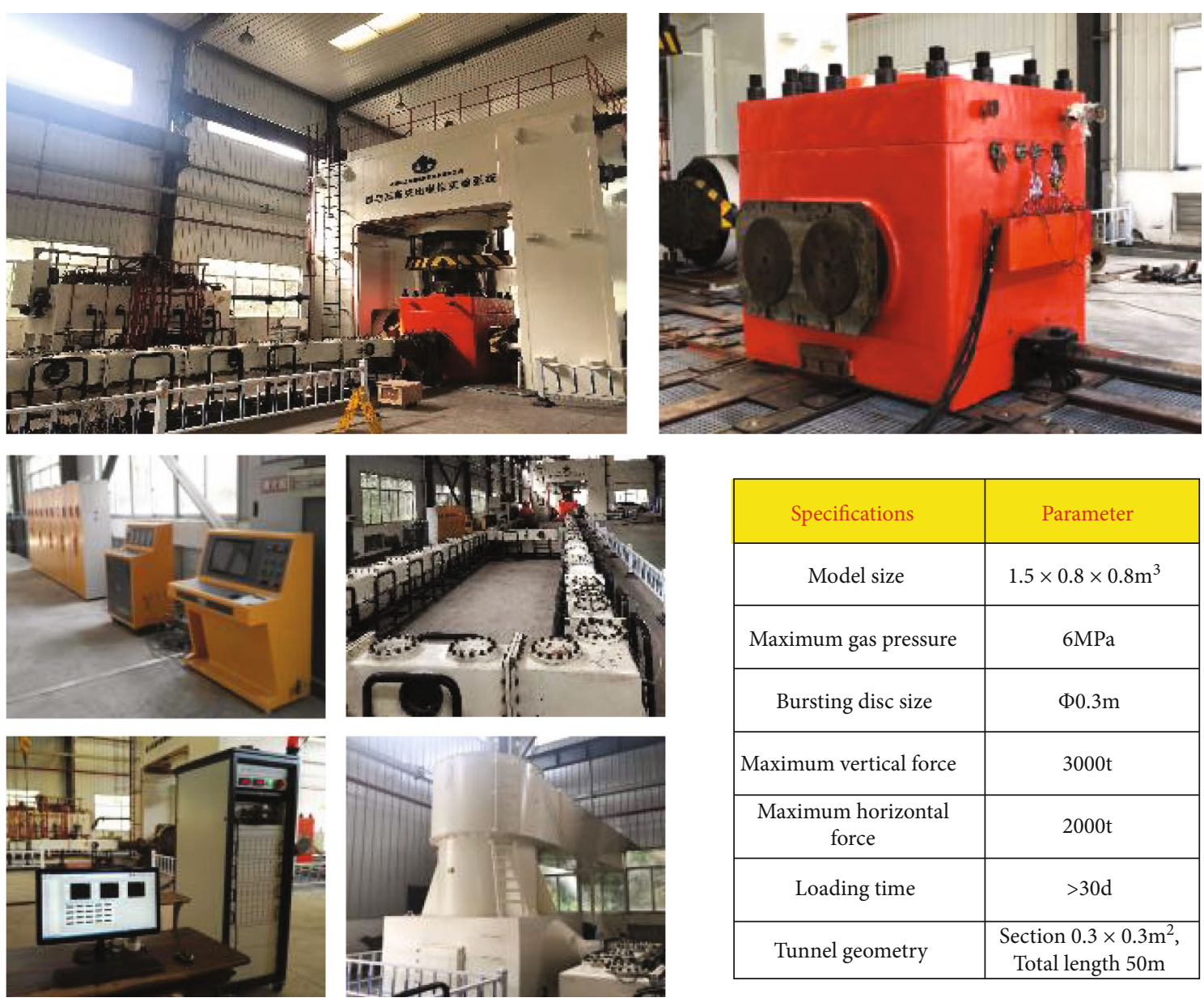

\begin{tabular}{|c|c|}
\hline Specifications & Parameter \\
\hline Model size & $1.5 \times 0.8 \times 0.8 \mathrm{~m}^{3}$ \\
\hline Maximum gas pressure & $6 \mathrm{MPa}$ \\
\hline Bursting disc size & $\Phi 0.3 \mathrm{~m}$ \\
\hline Maximum vertical force & $3000 \mathrm{t}$ \\
\hline $\begin{array}{c}\text { Maximum horizontal } \\
\text { force }\end{array}$ & $2000 \mathrm{t}$ \\
\hline $\begin{array}{c}\text { Loading time } \\
\text { Tunnel geometry }\end{array}$ & $\begin{array}{c}\text { Section } 0.3 \times 0.3 \mathrm{~m}^{2} \\
\text { Total length } 50 \mathrm{~m}\end{array}$ \\
\hline
\end{tabular}

FIgURE 1: Coal and gas outburst simulation experiment system.

the gas expansion further breaks the coal and throws it into the roadway [20], and the expansion work is proportional to the rate of gas release [2]. Due to the complexity of the coal and gas outburst mechanism, the use of large-scale coal and gas outburst testing equipment to explore the excitation conditions of coal and gas outburst in complex environments is the current development trend $[5,8,11]$.

Focusing on the characteristics of deep coal mining, China Coal Science and Industry Group Chongqing Research Institute Co., Ltd. has researched and developed a deep mine coal and rock gas dynamic disaster simulation experiment system. The maximum vertical loading capacity of the experimental system is $25 \mathrm{MPa}$, the maximum horizontal loading capacity is $16 \mathrm{MPa}$, the system stiffness is 3 $\times 10^{10} \mathrm{~N} / \mathrm{m}$, the maximum gas pressure is $6 \mathrm{MPa}$, and the minimum ground temperature reaches $60^{\circ} \mathrm{C}$ [21].

The coal and gas outburst simulation experiment system is composed of six parts: mechanical loading system, sealing and outburst generation system, inflation system, simulated roadway system, monitoring system, and dust removal system, as shown in Figure 1. The experimental system can simulate all the processes (incubation, occurrence, evolution, and termination) of coal and gas outburst. In addition to studying the cause mechanism and dynamic evolution char- acteristics of coal and gas outburst disasters, it can also study the migration of coal and gas outburst two-phase flow in roadways and the separation and accumulation of coal dust. This experimental system provides support for research on mine coal and gas outburst disaster-prevention-control.

During the test, a large amount of elastic energy is stored in the testing machine. When the rock sample is damaged, the elastic energy stored in the testing machine is suddenly released, which causes the sample to be further severely damaged. In order to avoid such damage, the stiffness of the testing machine must be improved to meet the needs of the experiment. In addition, the gas outburst simulation experiment system is a limited space, while the deep gas outburst is in a nearly infinite space. The above problems will affect the stability and error of the gas outburst simulation experiment system.

The article uses this experimental system to simulate a coal and rock gas outburst accident on the 11-2 seam 1331 (1) conveyor tunnel driving face of Huainan Dingji Coal Mine on April 19, 2009. Analyze the energy change in the process of gas outburst through the phenomenon of experimental results, and then determine whether the design of the testing machine meets the requirements of the simulation test. 


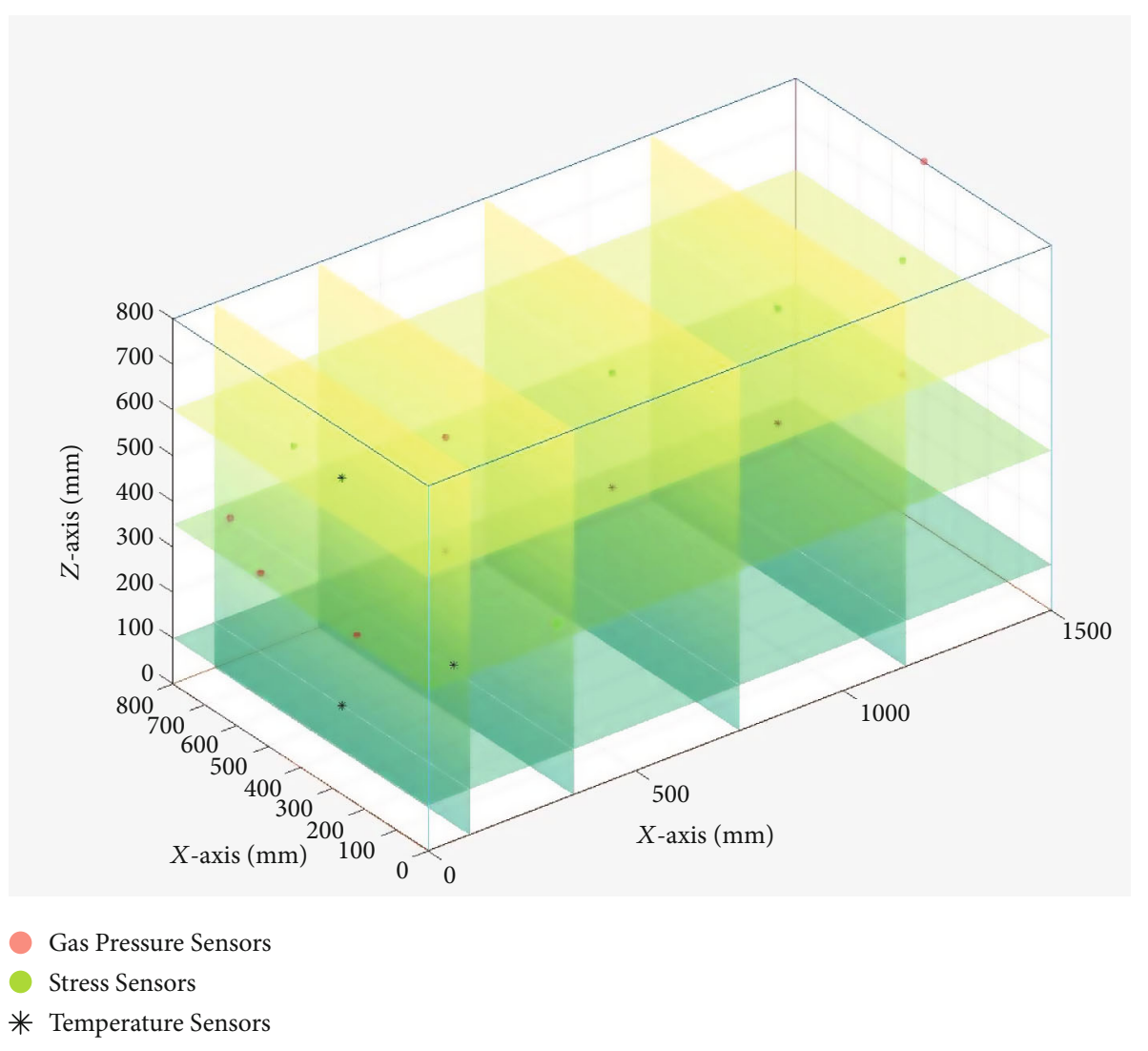

Figure 2: Position of the sensor in similar materials.

\section{Simulation Experiment}

The simulation experiment used $\mathrm{CO}_{2}$ as the experimental gas, and the rock block in the experiment (the size is $1.5 \mathrm{~m}$ $\times 0.8 \mathrm{~m} \times 0.8 \mathrm{~m}$ ) is a self-made similar material. Pulverized coal is the main component of similar materials (mass ratio is $78.16 \%$ ). In addition, the mass ratios of cement, sand, water, and activated carbon are $7 \%, 5.5 \%, 8.5 \%$, and $0.84 \%$, respectively. Similar materials are made by layering (4 layers). The precompression pressure is $25 \mathrm{MPa}$. The holding time for forming similar materials is 30 minutes, and the curing time for similar materials is 30 days. The mechanical properties of similar materials belong to soft rock. The uniaxial compressive strength of similar materials is $1.88 \mathrm{MPa}$, the elastic modulus is $178.62 \mathrm{MPa}$, the porosity is $2.99 \%$, and the density is $1590 \mathrm{~kg} / \mathrm{m}^{3}$. The adsorption constants $[2,20] \mathrm{a}$ and $\mathrm{b}$ of similar materials are 33.98 and 1.63 , respectively. The similarity ratio of the material is $1: 1$.

While making the similar model, the sensors are arranged inside the similar model. A total of 31 sensors are arranged in the similar model, including 12 gas pressure sensors, 13 in situ stress sensors, and 6 temperature sensors, as shown in Figure 2.

After preparing similar rocks, it is charged with $0.2 \mathrm{MPa}$ of $\mathrm{CO}_{2}$ to displace the air in the similar model. After $\mathrm{CO}_{2}$ displaces the air for a period of time, an initial lateral stress of 3.0 MPa and an axial stress of $16.0 \mathrm{MPa}$ are applied to similar models. Continuing, we also injected $\mathrm{CO}_{2}$ gas into the balance chamber of the explosive device and similar materials.
We keep the pressure difference between the two sides of the bursting disc less than its bursting pressure $0.4 \mathrm{MPa}$ and make similar materials basically reach the adsorption equilibrium. Fill the balance gas chamber of the device with overpressure gas greater than $0.4 \mathrm{MPa}$ to induce protrusions. The computer records the data during the experiment in real time. The high-speed acquisition is started when the $\mathrm{CO}_{2}$ gas outburst occurred. After the outburst of $\mathrm{CO}_{2}$ gas, the distribution of pulverized coal in the roadway and the shape characteristics of the outburst holes are collected. The schematic diagram of the experimental process is shown in Figure 3.

\section{Experimental Results}

Before analyzing the experimental results, we obtained the stiffness of the testing machine through CAE simulation $[22,23]$. It is found that the displacement in a certain direction has a linear relationship with the applied stress, as shown in Figure 4. The calculated longitudinal stiffness and transverse stiffness of the experimental machine are $1.5 \times 10^{10}$ $\mathrm{N} / \mathrm{m}$ and $4 \times 10^{10} \mathrm{~N} / \mathrm{m}$, respectively. There is a mutual influence between the horizontal indenter displacement and the longitudinal indenter displacement of the experimental machine. When the longitudinal indenter is loaded, the displacement ratio of the horizontal indenter is -0.218 ; when the horizontal indenter is loaded, the displacement ratio of the longitudinal indenter is -0.243 .

According to the similar proportion, the simulated outburst coal quantity is $39.74 \mathrm{t}$, and the actual outburst coal 


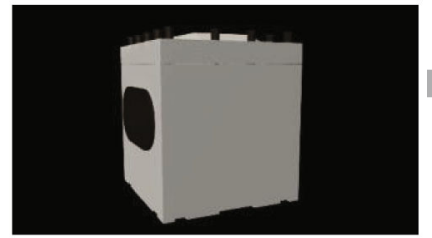

1 Make similar models in layers

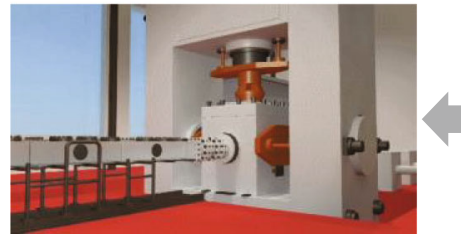

4 Information monitoring

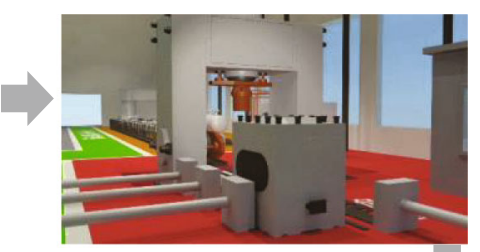

2 Loading stress

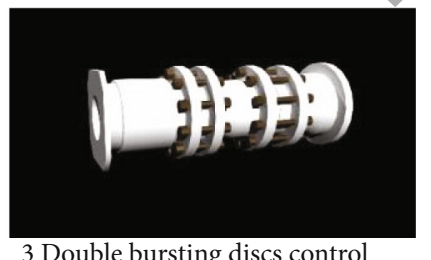

3 Double bursting discs control gas protruding

FIGURE 3: The schematic diagram of the experimental process.

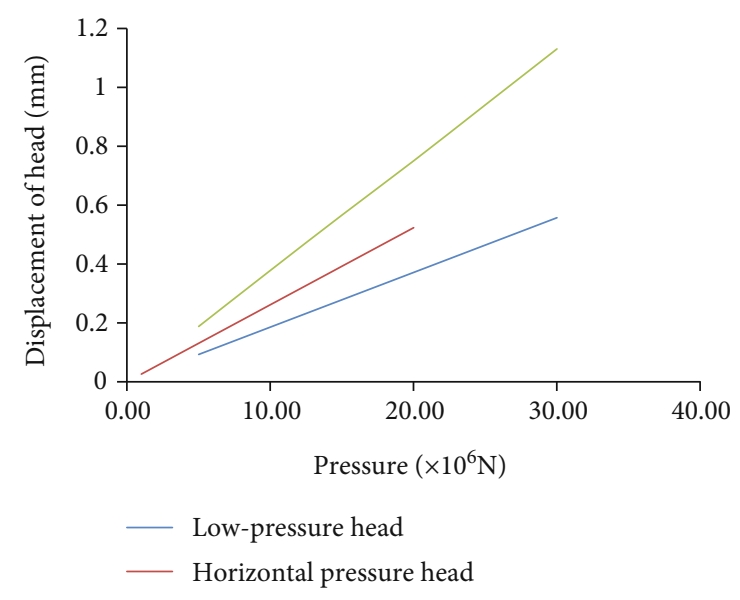

FIgURE 4: Indenter displacement curve of testing machine.

quantity in the field is $35 \mathrm{t}$. Considering the laboratory error and the statistical error of the field data, the experimental data are consistent with the actual situation in the field.

The energy storage in the experimental system before the gas outburst is calculated. The calculation results show that the deformation energy [24] of the experimental machine is $1.1 \times 10^{4} \mathrm{~J}$, and the deformation energy stored in similar materials is $5.7 \times 10^{5} \mathrm{~J}$. The volume of free $\mathrm{CO}_{2}$ gas in similar materials is $0.028704 \mathrm{~m}^{3}$, and the free gas storage energy is $1.17 \times 10^{4} \mathrm{~J}$. The mass of $\mathrm{CO}_{2}$ gas adsorbed in similar materials is $43.8 \mathrm{~kg}$, which is greater than the mass of free $\mathrm{CO}_{2}$ gas. The energy storage of adsorbed $\mathrm{CO}_{2}$ gas will be much greater than that of free gas [9].

The gas outburst experiment is actually the conversion of energy [11]. There are mainly four energy conversion channels: changes in temperature of similar materials, energy is converted into kinetic energy of coal and air, energy is used for the rupture of similar materials, and energy is used for system dissipation. Damped vibration is the main channel for energy dissipation [11-13].

During the process of coal and gas outburst, the temperature of similar materials will change due to energy conversion and gas desorption. As shown in Figure 5, the temperature changes during the experiment. To prevent the

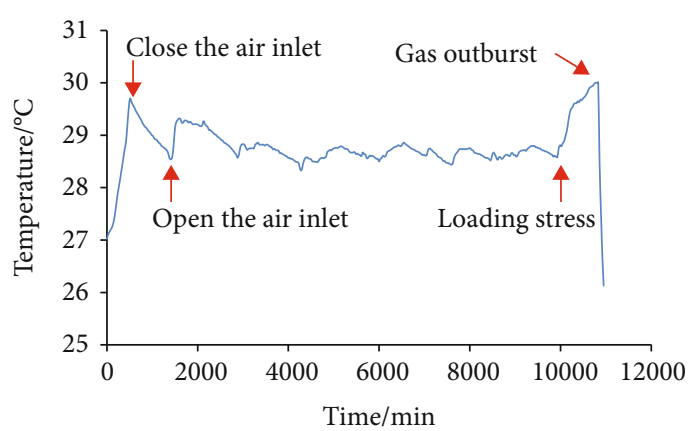

FIGURE 5: The gas temperature changes in similar materials during the experiment.

temperature sensor from being damaged during the experiment, the thermocouple was placed in a cavity of similar material. The actual temperature measured by the thermocouple sensor is the temperature of $\mathrm{CO}_{2}$ gas in similar materials. Therefore, the temperature of $\mathrm{CO}_{2}$ gas is obviously affected by pressure, which is reflected in the process of $\mathrm{CO}_{2}$ gas pressurization and saturation. The temperature dropped by 3 degrees after the gas outburst occurred, which was caused by the expansion of $\mathrm{CO}_{2}$ gas. In this process, the energy released by the temperature decrease is about $403 \mathrm{~J}$.

The shape of the hole after the $\mathrm{CO}_{2}$ gas outburst is irregular semiellipsoid. The depth of the hole is about $15 \mathrm{~cm}$, and the maximum width of the hole is $30 \mathrm{~cm}$. The upper part of the coal wall in the hole showed obvious layered fracture. At the same time, most of the ejected coal is in the form of flakes, and the stacking height of the coal flakes accounts for more than $2 / 3$ of the hole diameter.

During the outburst process, the broken similar materials are thrown into the tunnel and deposited under the action of gas, which reflects the strength of the outburst. In this similar simulation experiment, a total of $18.09 \mathrm{~kg}$ of similar materials were thrown out, and the farthest distance from the hole was $3.3 \mathrm{~m}$. After the experiment, the cuttings in the roadway were divided into 5 areas for sampling, weighing, and screening. The results are shown in Figures 6 and 7. As shown in Figure 6 , the quality of thrown cuttings is decreasing along 


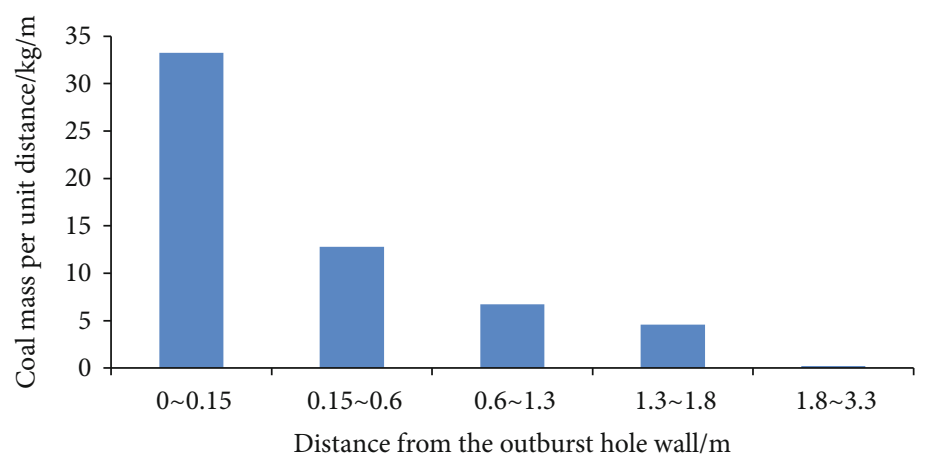

FIGURE 6: Mass distribution of thrown cuttings.

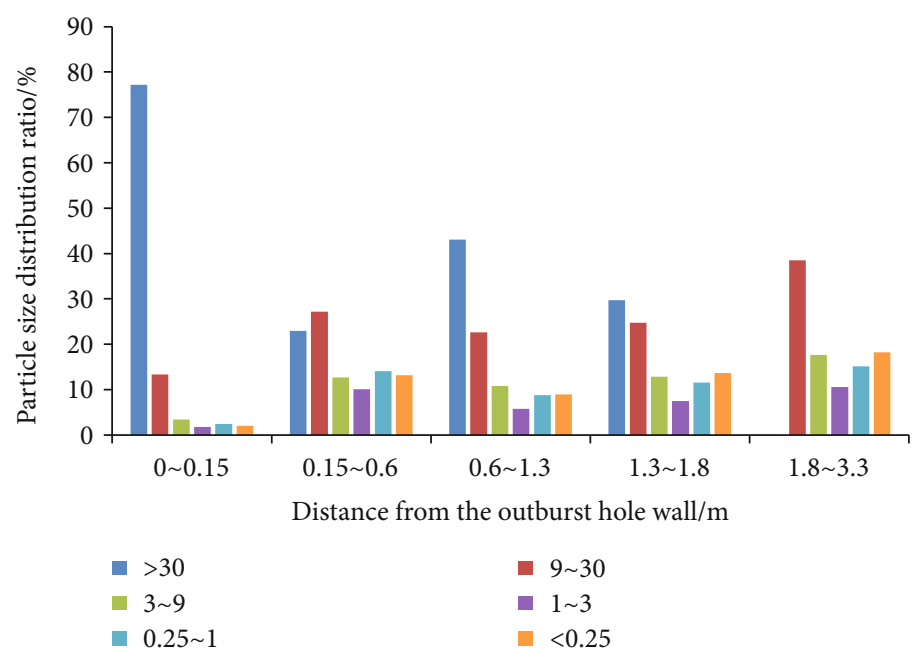

FIgURE 7: The particle size distribution diagram of thrown cuttings in different areas.

the roadway. Within $0.6 \mathrm{~m}$ from the hole, the mass of thrown cuttings accounts for $59.4 \%$. Figure 7 shows the particle size distribution of cuttings thrown in different areas. Figure 7 shows that more than $80 \%$ of the cuttings in the hole $(0 \sim 0.15 \mathrm{~m})$ are larger than $9 \mathrm{~mm}$. The particle size distribution of cuttings in other regions is the same, and the proportion of cuttings' particle size in each region shows a trend of first decreasing and then increasing as the particle size decreases. In each region, the cuttings with a particle size greater than $9 \mathrm{~mm}$ or less than $1 \mathrm{~mm}$ accounted for the majority, while the medium-sized cuttings accounted for a relatively small proportion. The energy used to throw out cuttings by calculation is about $550 \mathrm{~J}$.

In the simulated gas outburst experiment, the gas pressure in similar rock blocks is shown in Figure 8. The similar material near the hole loses support due to sudden exposure, and the accumulated elastic energy and gas compression energy are quickly released. This causes similar materials to be broken and thrown out to form the initial protruding holes. After the outburst, similar rock blocks ruptured, forming integrated staggered fissures. The closer to the hole, the greater the crack density is. The gas pressure near the hole quickly decays to $0.0 \mathrm{MPa}$, as shown in Figure 8(a). The gas pressure in similar materials farther from the hole gradually decreases, as shown in Figure 8(b).
There is still some gas in similar materials after the gas outburst. The energy stored in similar materials is not completely released [10]. After the initial pores are formed by the gas outburst, the test conditions have higher stress and lower porosity, and the crack density far away from the hole is small and gas permeability is weak. The newly desorbed $\mathrm{CO}_{2}$ gas failed to accumulate enough energy to further break and throw similar materials, so the protrusion was terminated. Therefore, the duration of the outburst under the stress is shorter.

After the outburst occurs, the adsorbed $\mathrm{CO}_{2}$ in similar materials is quickly desorbed and gushes out into the roadway space, causing the $\mathrm{CO}_{2}$ concentration near the holes in the roadway to increase rapidly, reaching $15.4 \%$ in a very short time. With the end of the outburst, the $\mathrm{CO}_{2}$ gas concentration gradually decreases. There is still a relatively stable source of $\mathrm{CO}_{2}$ gas behind the protruding hole in a short time, so the concentration in the tunnel gradually reaches a stable value of $3.15 \%$. By observing the gas pressure in similar rock blocks, it is concluded that after 2000 seconds, the mass of compressed free gas in similar materials accounts for $60 \%$ of the mass before the experiment. At the end of the experiment, the gas pressure in similar materials was generally around $0.2 \mathrm{MPa}$, and the $\mathrm{CO}_{2}$ gas in similar materials was being stably released. Therefore, it is calculated that the 


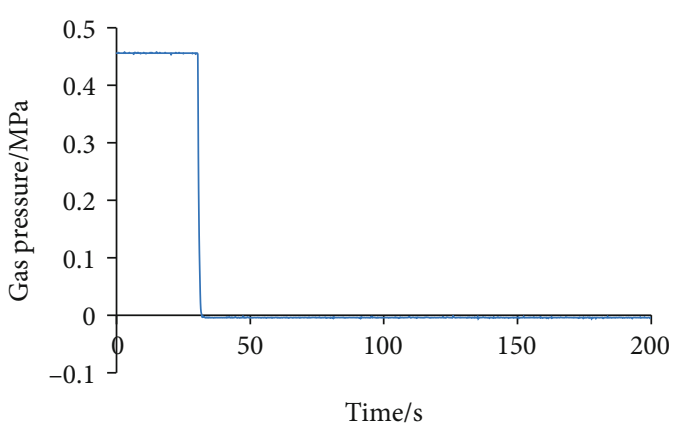

(a)

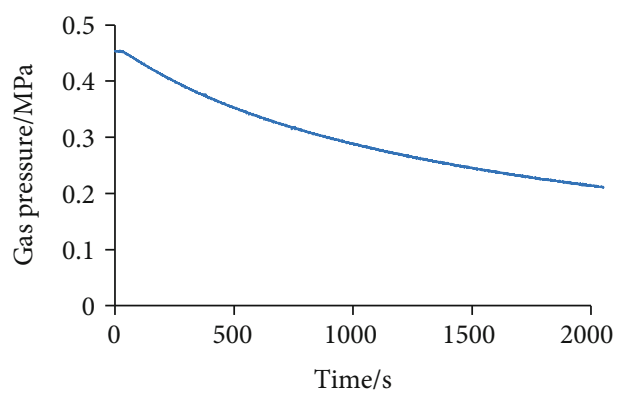

(b)

FIGURE 8: Gas pressure change curve.

energy released by $\mathrm{CO}_{2}$ gas in similar materials is greater than $3500 \mathrm{~J}$.

The uniaxial compression curve of a similar material sample is shown in Figure 9. A rough calculation shows that the energy density absorbed per unit volume of the standard sample is $22200 \mathrm{~J} / \mathrm{m}^{3}$ when it is broken. The damaged sample had multiple main fracture and was divided into several large pieces, but did not collapse. The elastic energy absorbed by the specimen under uniaxial compression is used for specimen failure and cracking. We believe that the energy density required for similar materials to form the cracks shown in Figure 9 is $22200 \mathrm{~J} / \mathrm{m}^{3}$. In the entire similar material, the broken bodies are concentrated in the hole, and the crack density in the similar material gradually decreases with the increase of the distance of the hole. According to the density of cracks in similar materials after the experiment, it can be estimated that the energy used for the destruction and cracking of similar materials during the experiment is about $2220 \mathrm{~J}$.

The released energy comes from the decrease of temperature and the release of $\mathrm{CO}_{2}$ gas compression energy in similar materials. The compression energy released by the $\mathrm{CO}_{2}$ gas in similar materials is the most important energy source.

\section{Analysis of Testing Machine Parameters}

Compared with the infinite space of on-site working conditions, the biggest difference is that the experimental system is a limited space. The parameters of the testing machine will determine the stability and accuracy of the simulation experiment system. This will be analyzed below.

First, analyze the influence of the stored deformation energy of the testing machine on the accuracy of the simulation experiment. The similar material after the $\mathrm{CO}_{2}$ outburst still has the pressure-bearing capacity, and the stress of the internal observation point before and after the gas outburst is shown in Figure 10. It can be concluded from the figure that the stress near the hole of the similar material has decreased, while the stress far away from the hole has increased.

During the experiment, the displacement of the indenter of the testing machine was almost 0.0 , and the stress increase of the indenter of the testing machine was about $0.1 \mathrm{MPa}$. This phenomenon is consistent with the observation of onsite working conditions. During the gas outburst experiment,

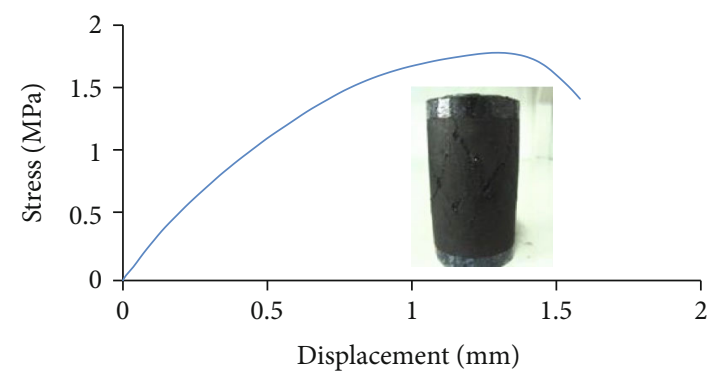

FIGURE 9: Uniaxial compression curve of similar materials.

the hydraulic cylinder of the testing machine was in a locked state. Therefore, the testing machine can be regarded as a compression spring with one end fixed and one end acting on similar materials. The increase in stress indicates that the spring is further compressed, and the mechanical energy stored by the testing machine increases. Experimental phenomena show that similar materials have new cracks, and these cracks increase the nominal volume of similar materials. The process of gas outburst is the process of expansion of similar materials. In addition, these cracks reduce the elastic modulus of similar materials. Through the above calculation and analysis, it can be judged that the deformation energy stored in similar materials has slightly increased. The energy increase of the testing machine and similar materials does not exceed $1000 \mathrm{~J}$.

In the field conditions, the change of stress and strain at infinity is almost zero. During this experiment, the displacement of the indenter of the testing machine is very small, and the change in stress is very small. The stiffness of the testing machine meets the needs of gas outburst simulation experiments. The size of similar materials can be further increased to increase the accuracy of the simulation experiment.

Second, we analyze the impact of the vibration characteristics of the testing machine on the accuracy and stability of the simulation experiment [25]. According to the above analysis, the energy released during the experiment is greater than the energy absorbed by the system, and the excess energy is dissipated by the experimental system. Damping vibration of the experimental system is the main way of energy dissipation $[26,27]$. According to the geometric structure of the experimental system, it is divided into experimental machines and similar materials. Gas outburst will cause 


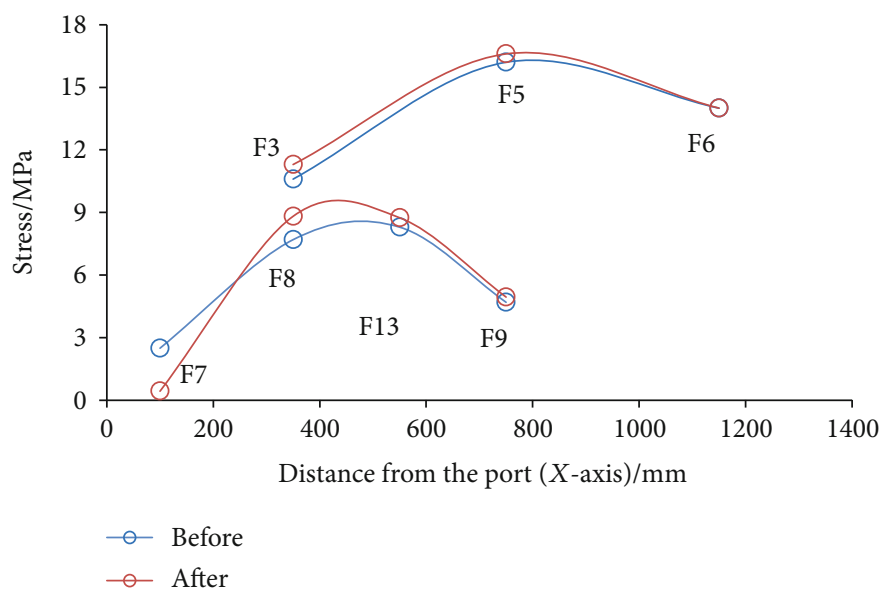

Figure 10: Stress of observation points in similar materials before and after gas outburst.

coupling vibration between the testing machine and similar materials. The vibration excitation of the testing machine comes from similar materials; the vibration excitation of similar materials comes from the vibration of the testing machine and the instantaneous release of energy when the gas burst occurred.

Data show that the natural vibration frequency of relatively complete rock is above $1000 \mathrm{~Hz}$ [28]. The test results show that the natural frequency of similar materials is $2170 \mathrm{~Hz}$. Similar materials are similar to rocks, and the propagation speed of stress waves is between 3.2 and $7.0 \mathrm{~km} / \mathrm{s}$ [29]. Therefore, in the experimental simulation process, the deformation of similar materials can be considered to be instantaneous. The damping ratio of similar materials is between 0.06 and 0.11 [30], while the damping ratio of broken rock is higher [31]. The process of stress wave propagation in similar materials is a process of energy dissipation. The higher the rock vibration frequency is, the faster the energy decay is. The frequency range of seismic waves excited by artificial earthquakes is generally between 2 and $50 \mathrm{~Hz}$ [32]. We can judge that the vibration excitation frequency of similar materials to the testing machine is in the range of $2-50 \mathrm{~Hz}$

We use the ANSYS WORKBENCH finite element software to analyze the natural frequency of the testing machine. The natural frequency and the vibration mode of testing machine are obtained by calculation. The natural frequencies of the first six orders of vibration are $22.47 \mathrm{~Hz}, 29.89 \mathrm{~Hz}$, $43.01 \mathrm{~Hz}, 93.09 \mathrm{~Hz}, 99.971 \mathrm{~Hz}$, and $128.35 \mathrm{~Hz}$. The vibration excitation frequency of similar materials is low, so the highorder frequency vibration of the experimental machine does not need to be considered. The frequency of the fourth-order mode is $93.09 \mathrm{~Hz}$, and this mode is the main vibration mode excited by similar materials. The excitation frequency received by the testing machine is lower than $93.09 \mathrm{~Hz}$. The difference between the natural frequency of the testing machine and the excitation frequency is more conducive to energy dissipation. The analysis can show that the experimental system does not produce obvious resonance phenomenon during the experiment, which has little influence on the experimental results.
In site conditions, most of the energy is transmitted to the distant place in the form of seismic waves, and the energy is gradually dissipated in the process of transmission. In the experimental simulation, part of the vibration wave is reflected from the interface, and part of the vibration wave is absorbed by the testing machine. The greater the energy absorbed by the testing machine, the greater the simulation accuracy of the testing machine. Adding a damping structure to the testing machine enables the testing machine to absorb and dissipate more energy. The experimental simulation system in this article adds multiple high damping devices to absorb energy. In summary, the parameters of the testing machine have minimal impact on the accuracy of the simulation experiment.

\section{Conclusions}

In this paper, the simulation experiment of coal and gas outburst is carried out by using the simulation experiment system of deep-well coal and rock gas dynamic disaster. The energy conversion in the process of gas outburst is analyzed through experimental phenomena and results. Then, according to the experimental phenomenon and CAE simulation, the influence of the parameters of the testing machine on the stability and accuracy of the gas outburst simulation experiment is judged. The main conclusions obtained are as follows:

(1) Gas outburst is actually the transformation of energy. The released energy comes from the decrease of temperature and the release of $\mathrm{CO}_{2}$ gas compression energy in similar materials. The compression energy released by the $\mathrm{CO}_{2}$ gas in similar materials is the most important energy source

(2) Simulation experiments show that cracks increase the nominal volume of similar materials. These breaks reduce the elastic modulus of similar materials and slightly increase the deformation energy stored in similar materials 
(3) The parameters of the testing machine satisfy the needs of the experiment. The displacement and pressure of the indenter remained basically unchanged during the experiment. The vibration excitation frequency transmitted to the testing machine is 2$50 \mathrm{~Hz}$, and the natural frequency of the testing machine is $93.09 \mathrm{~Hz}$. The system will not produce resonance to meet the needs of experimental stability. It is recommended to add a damping structure to the testing machine so that the testing machine can dissipate more energy

\section{Data Availability}

The data used to support the findings of this study are available from the corresponding author upon request.

\section{Conflicts of Interest}

The authors declare that they have no conflicts of interest.

\section{Acknowledgments}

This study was supported by the National Natural Science Foundation of China (51974358, 51874348, and 51774319), Science and Technology Innovation and Entrepreneurship Fund of China Coal Technology Engineering Group (2019TD-QN037 and 2019-TD-QN040), Natural Science Foundation of Chongqing (cstc2020jcyj-msxmX1052 and cstc2019jcyj-msxmX0531), and Chongqing Science Fund for Distinguished Young Scholars (cstc2019jcyjjqX0019).

\section{References}

[1] C. Zhang, J. Xu, G. Yin, S. Peng, Q. Li, and Y. Chen, “A novel large-scale multifunctional apparatus to study the disaster dynamics and gas flow mechanism in coal mines," Rock Mechanics and Rock Engineering, vol. 52, no. 8, pp. 28892898, 2019.

[2] K. Jin, Y. Cheng, T. Ren et al., "Experimental investigation on the formation and transport mechanism of outburst coal-gas flow: implications for the role of gas desorption in the development stage of outburst," International Journal of Coal Geology, vol. 194, pp. 45-58, 2018.

[3] W. Yin, G. Fu, C. Yang, Z. Jiang, K. Zhu, and Y. Gao, "Fatal gas explosion accidents on Chinese coal mines and the characteristics of unsafe behaviors: 2000-2014," Safety Science, vol. 92, pp. 173-179, 2017.

[4] R. Liu, W. Cheng, Y. Yu, and Q. Xu, "Human factors analysis of major coal mine accidents in China based on the HFACSCM model and AHP method," International Journal of Industrial Ergonomics, vol. 68, pp. 270-279, 2018.

[5] L. Yuan, "Control of coal and gas outbursts in Huainan mines in China: a review," Journal of Rock Mechanics and Geotechnical Engineering, vol. 8, no. 4, pp. 559-567, 2016.

[6] H. Sun, J. Cao, M. Li et al., "Experimental research on the impactive dynamic effect of gas-pulverized coal of coal and gas outburst," Energies, vol. 11, no. 4, p. 797, 2018.

[7] J. Cao, L. Dai, H. Sun et al., "Experimental study of the impact of gas adsorption on coal and gas outburst dynamic effects,"
Process Safety and Environmental Protection, vol. 128, pp. 158-166, 2019.

[8] Y. Lu, H. Wang, B. Xia, X. Li, Z. Ge, and J. R. Tang, "Development of a multi-functional physical model testing system for deep coal petrography engineering," Rock Mechanics and Rock Engineering, vol. 50, no. 2, pp. 269-283, 2017.

[9] J. Sobczyk, "A comparison of the influence of adsorbed gases on gas stresses leading to coal and gas outburst," Fuel, vol. 115, pp. 288-294, 2014.

[10] A.-D. Alexeev, V.-N. Revva, N.-A. Alyshev, and D. M. Zhitlyonok, "True triaxial loading apparatus and its application to coal outburst prediction," International Journal of Coal Geology, vol. 58, no. 4, pp. 245-250, 2004.

[11] B. Nie, Y. Ma, S. Hu, and J. Meng, "Laboratory study phenomenon of coal and gas outburst based on a mid-scale simulation system," Scientific Reports, vol. 9, no. 1, article 15005, 2019.

[12] H. Liu, B. Lin, J. Mou, and W. Yang, "Mechanical evolution mechanism of coal and gas outburst," Rock Mechanics and Rock Engineering, vol. 52, no. 5, pp. 1591-1597, 2019.

[13] S. Zhi and E. Derek, "The role of gas desorption on gas outbursts in underground mining of coal," Geomechanics and Geophysics for Geo-Energy and Geo-Resources, vol. 2, no. 3, pp. 151-171, 2016.

[14] T. Xu, C.-A. Tang, T.-H. Yang, W. C. Zhu, and J. Liu, "Numerical investigation of coal and gas outbursts in underground collieries," International Journal of Rock Mechanics and Mining Sciences, vol. 43, no. 6, pp. 905-919, 2006.

[15] H. Li, Z. Feng, D. Zhao, and D. Duan, "Simulation experiment and acoustic emission study on coal and gas outburst," Rock Mechanics and Rock Engineering, vol. 50, no. 8, pp. 21932205, 2017.

[16] J. Hongwei, H. Qianting, and L. Yanbao, "Failure mechanism of coal and gas outburst initiation," Procedia Engineering, vol. 26, pp. 1352-1360, 2011.

[17] G. Yin, C. Jiang, J. G. Wang, J. Xu, D. Zhang, and G. Huang, “A new experimental apparatus for coal and gas outburst simulation," Rock Mechanics and Rock Engineering, vol. 49, no. 5, pp. 2005-2013, 2016.

[18] Q. Tu, Y. Cheng, P. Guo, J. Jiang, L. Wang, and R. Zhang, "Experimental study of coal and gas outbursts related to gasenriched areas," Rock Mechanics and Rock Engineering, vol. 49, no. 9, pp. 3769-3781, 2016.

[19] G. Wang, W. Cheng, Z. Qingtao, and L. Sun, "Design of simulation experiment and its application system of outburst in uncovering coal seam in cross-cut," Rock and Soil Mechanics, vol. 34, no. 4, pp. 1202-1210, 2013.

[20] A. Zhou, K. Wang, L. Wang, F. du, and Z. Li, "Numerical simulation for propagation characteristics of shock wave and gas flow induced by outburst intensity," International Journal of Mining Science and Technology, vol. 25, no. 1, pp. 107-112, 2015.

[21] J. Cao, H. Sun, B. Wang et al., "A novel large-scale threedimensional apparatus to study mechanisms of coal and gas outburst," International Journal of Rock Mechanics and Mining Sciences, vol. 118, pp. 52-62, 2019.

[22] M.-W. Fu, M.-S. Yong, and T. Muramatsu, "Die fatigue life design and assessment via CAE simulation," The International Journal of Advanced Manufacturing Technology, vol. 35, no. 910, pp. 843-851, 2008.

[23] D. Krzikalla, A. Slíva, J. Měsíček, and J. Petrů, “On modelling of simulation model for racing car frame torsional stiffness 
analysis," Alexandria Engineering Journal, vol. 59, no. 6, pp. 5123-5133, 2020.

[24] S. Zhang, W. Liu, and H. Lv, "Creep energy damage model of rock graded loading," Results in Physics, vol. 12, pp. 11191125, 2019.

[25] L. Dong, J. Wang, X. Li, and K. Peng, "Dynamic stability analysis of rockmass: a review," Advances in Civil Engineering, vol. 2018, Article ID 4270187, 22 pages, 2018.

[26] I. López, J.-M. Busturia, and H. Nijmeijer, "Energy dissipation of a friction damper," Journal of Sound and Vibration, vol. 278, no. 3, pp. 539-561, 2004.

[27] G. Bianchi, S. Cagna, N. Cau, and F. Paolucci, "Analysis of vibration damping in machine tools," Procedia CIRP, vol. 21, pp. 367-372, 2014.

[28] S. Li, S. Tian, W. Li, T. Yan, and F. Bi, "Research on the resonance characteristics of rock under harmonic excitation," Shock and Vibration, vol. 2019, 11 pages, 2019.

[29] J. Zhou, W. Lu, P. Yan, M. Chen, and G. Wang, "Frequencydependent attenuation of blasting vibration waves," Rock Mechanics and Rock Engineering, vol. 49, no. 10, pp. 40614072, 2016.

[30] Z. Song and C. Su, "Computation of Rayleigh damping coefficients for the seismic analysis of a hydro-powerhouse," Shock and Vibration, vol. 2017, Article ID 2046345, 11 pages, 2017.

[31] Y. Takahashi, T. Sasaoka, W. Sugeng et al., "Study on prediction of ground vibration in consideration of damping effect by fragment in the rock mass," Journal of Geoscience and Environment Protection, vol. 6, no. 6, pp. 1-11, 2018.

[32] H. Yuan, X. Liu, Y. Liu, H. Bian, W. Chen, and Y. Wang, "Analysis of acoustic wave frequency spectrum characters of rock mass under blasting damage based on the HHT method," Advances in Civil Engineering, vol. 2018, Article ID 9207476, 8 pages, 2018. 